\title{
Las víctimas como lugar teológico
}

\author{
José Ignacio González Faus, \\ San Cugat del Vallés, Barcelona, \\ Centro de Reflexión Teológica, \\ San Salvador.
}

J. Sobrino, La fe en Jesucristo. Ensayo desde las víctimas, Trotta, Madrid 1999, 477 págs. ISBN 84-8164-268-1. 24X14 cms.

(El libro ha sido publicado simultáneamente en UCA Editores, San Salvador 1999, 613 págs.)

Llega por fin el esperado segundo volumen de la cristología de Jon Sobrino. El primero apareció en 1991 y quería ser una lectura "histórico-teológica" de la figura de Jesús, que comenzaba con unas largas consideraciones metodológicas y concluía en la muerte de Jesús. El presente volumen se subtitula "ensayo desde las víctimas". Ensayo quiere decir que no es un libro "de texto" (aunque se le podrá utilizar como tal y se convertirá sin duda en un libro "de referencia"). Lo de las víctimas requiere una mayor explicación: ante el repetido eslogan de que, en estos últimos años, se ha producido un "cambio de paradigmas", Sobrino comienza preguntándose si no hay algo "metaparadigmático", algo que esté más allá de ese cambio. Pues bien, ese algo que no ha cambiado siguen siendo las víctimas: en todo caso, lo único que ha cambiado es que antes contaban (como "oprimidos") y ahora ni siquiera cuentan (son simplemente "excluidos", no tenidos en cuenta como si fueran inexistentes). Lo que no ha cambiado es ese "peso de lo real" (p. 18).

Desde el prólogo se nos avisa, por tanto, que estamos ante un libro "parcial". Pero se nos explica que se trata de una parcialidad exigida, tanto por la realidad del mundo como por la misma fe cristiana. Por desgracia (y éste será uno de los hilos conductores del libro), las cristologías se centraron desde muy pronto "en la persona de Cristo", olvidando "la causa de Jesús", que era el reino para los 
pobres (éste había sido uno de los ejes del tomo anterior). Con ello, en el mejor de los casos, las víctimas se quedaron sólo en el campo de la ética, no en el de la identidad teologal cristiana. Se reconoce también que hacer teología "desde las víctimas" es enormemente difícil, porque ellas no pueden hacerla, y quien puede hacer teología no es una víctima. Pero, aun aceptando la verdad de esta objeción, se le responde que, al menos en el contacto con las víctimas, brota una luz nueva, que las convierte en una especie de sacramento. Con esta confesión reconoce también el autor otra forma de parcialidad, no puede entrar en otros intentos cristológicos del momento (feministas, asiáticos...), aunque éstos son valiosos precisamente porque introducen "otras formas de alteridad".

Si el subtítulo da cuenta de esta óptica del libro, su mismo título nos avisa que se trata de un libro creyente: si el tomo anterior quiso encarar la historia de Jesús (aunque lo hiciera sin abandonar la fe en él), este tomo es la historia de la fe de unos seres humanos (aunque esa fe tenga un referente terreno, que es Jesús de Nazaret). Pero esa fe es de tal tipo que implica una toma de postura, no sólo ante Jesús, sino ante la realidad total, como se irá viendo a lo largo de la obra.

Expuesto el enfoque de la obra queda decir algo de su estructura. Tres partes dedicadas a la resurrección de Jesús, a los títulos cristológicos del Nuevo Testamento y a la dogmática conciliar. La primera parte muestra cómo la consideración de la resurrección desde la esperanza de las víctimas, revela a Dios como Dios de las víctimas y abre la posibilidad de vivir como resucitados. La segunda parte se estructura mostrando el cambio que hace Dios en todos los títulos de Jesús, éstos no proclaman un caso más de un significado general y previamente conocido, sino que es el mismo Jesús el que da un contenido nuevo a lo que significa ser Señor, Mesías..., etc. En cambio, la tercera parte intenta mostrar el cambio de significado que hace Jesús en la noción de Dios (al relacionarla con la totalidad de lo real, con lo humano y con el sufrimiento - frente a cualquier deísmo-, y al poner un camino de seguimiento y exigencia en el acceso a Dios).

Elegiremos algún punto que exponer de cada una de esas tres partes.

\section{El problema hermenéutico de la resurrección}

La resurreción de Jesús es, por un lado, indecible e inexplicable porque se trata de un acontecimiento escatológico, sin parangón en ningún hecho de la historia. Pero, por otro lado, no podría ser anunciada si no "responde de alguna manera, aunque superándola, a alguna expectativa basada en la naturaleza de los seres humanos" (p. 33). En efecto, Sobrino descubre (y describe) cómo todos los teólogos europeos, para hablar de la resurrección, han tenido "presupuestos hermenéuticos que son realidades antropológicas" (p. 41): la seriedad de la existencia para Bultmann, el proseguimiento de la causa de Jesús para W. Marxsen; la esperanza en el futuro anticipado para Pannenberg y Moltmann (con sus dife- 
rencias) y, para Rahner, la definitividad o el triunfo último de la vida y de Dios, ya en la historia, a pesar de la aniquilación por la muerte.

Aprende ahí Sobrino que, aunque "no se puede ir a los textos neotestamentarios con el presupuesto de que ya sabemos de antemano lo que significa resurrección" (p. 55), sin embargo, para comprenderla, el mismo Nuevo Testamento exige "algún tipo de actitud previa": "una apertura a la gracia, una esperanza última, y alguna afinidad entre la vida presente del lector y lo que se anuncia como acaecido en Jesús" (cfr. p. 56).

Buscando la concreción latinoamericana de esas actitudes, constata el autor que "desde América Latina se ha ido reformulando la utopía en que consiste la resurrección y la esperanza necesaria para acceder a ella desde el débil y el oprimido" (p. 58). Esto le permite establecer el que considera horizonte hermenéutico más apto para el anuncio de la resurrección: "como ese Jesús es víctima inocente — es el crucificado—, su resurrección expresa no sólo el poder de Dios sobre la muerte, sino, en directo, el poder de Dios sobre la injusticia que produce víctimas" (p. 36).

Establecido esto, Sobrino sitúa en ese horizonte aquellas dimensiones antropológicas que expresan la totalidad del ser humano y que, para él, pueden resumirse en la famosa triple pregunta de Kant (qué podemos esperar, qué debemos hacer, qué podemos saber) a la que añadirá una cuarta, muy en sintonía con el autor, qué podemos celebrar. Desde las víctimas, la resurrección ilumina esas dimensiones humanas fundamentales. Veámoslo.

La esperanza de las víctimas no es simplemente el triunfo de la vida sobre la muerte, sino sobre la muerte injusta; o el triunfo de la justicia sobre la injusticia y de la víctima sobre el verdugo. Sobrino muestra, además, que es de esta manera y desde esta esperanza como nació en el Antiguo Testamento la primera esperanza en la resurrección final (con la cual empalma la resurrección de Jesús): "el mensaje de la apocalíptica es la esperanza en el poder de Dios para rehacer un mundo injusto y para hacer justicia a las víctimas" (p. 67). Por eso puede concluir afirmando que "la resurrección de Jesús es esperanza en primer lugar para los crucificados de la historia. Dios resucitó a un crucificado y desde entonces hay esperanza para los crucificados" (p. 70 subrayado del autor). Esa es además una esperanza que no puede ser tratada de egocéntrica o egoísta (éste era el argumento de muchos militantes marxistas de antaño contra los cristianos: se comprometen pero, por interés propio, para "ganar el cielo", etc.). Puesto que es "una esperanza descentrada" (p. 72).

Pero es además una esperanza que implica una praxis. En ello hay también coherencia con el Nuevo Testamento, para el que las apariciones pascuales no pretenden crear simplemente meros videntes o espectadores, sino testigos, enviados ("resurrección de Jesús y conciencia de misión parecen ir inseparablemente unidas", p. 75). La "predicación del hecho" ha de ir acompañada del "ser- 
vicio al contenido" (llevado hasta la disponibilidad a convertirse en víctima, puesto que la praxis a favor de los maltratados siempre implica conflictividad y hasta persecución).

Lo que sabe el creyente en la resurrección es que la historia está bajo la promesa que aquélla implica. Aceptar la realidad como promesa supone dos actitudes que Sobrino califica como apertura a la gratuidad y "castidad de la inteligencia" ("una inteligencia que no quiera tocarlo todo, decidir sobre todo", p. 84) y que tienen mucho que ver con esa categoría tan fundamental de todo su pensamiento, que él llama "honradez con lo real".

Esto es lo que me parece más destacable del estudio de la resurrección: el acercamiento hermenéutico, al que luego sigue un acercamiento histórico y otro teológico, que ya no puedo exponer. Aunque conviene evocar al menos, en el acercamiento histórico, el esfuerzo por describir - con todas las salvedades y distancias que convenga, pero sin renunciar por ello al esfuerzo- algo así como "analogías de experiencias pascuales" a lo largo de la historia y en la lucha por las víctimas. Partiendo de una afirmación de Rahner (que otros repiten de forma parecida): "el resucitado da testimonio de que él mismo vive", el autor intenta describir algunas experiencias "de irrupción de algo quasi-escatológico en nuestra realidad" (p. 112): son experiencias en las que parece — por así decir-que "la realidad toma la iniciativa y se desvela", pero se desvela "la realidad en ultimidad", de tal manera que ese desvelarse es experimentado "con agradecimiento", como don que no corresponde a merecimientos o expectativas anteriores. Tales experiencias, además, "suelen marcar existencialmente la vida, generan comunidad (aunque en su comienzo las hagan personas individuales) y dan lugar a un tipo de vida "marcada por la esperanza mantenida contra la negatividad" (pp. 113-114). En resumen - y por rápida que sea esta síntesis— sin formularlo así, y quizá sin darse cuenta, Sobrino traza ahí el empalme que lleva desde la resurrección a "pentecostés" y a la pneumatología.

\section{Los títulos cristológicos neotestamentarios}

Las experiencias vividas después de la resurrección fueron de tal magnitud que reclamaban no sólo una fe renovada, sino una fe nueva. Una fe que relacionaba con Dios los acontecimientos del destino de Jesús y luego los de su vida personal. Y que por eso ya no sabía pensar a Dios sin Jesús, ni pensar a Jesús sin mirarlo como perteneciente a la realidad de Dios (transfiguración, bautismo, nacimiento, preexistencia, parecen marcar los hitos de este proceso englobador).

Pero decir que toda la vida de Jesús revela a Dios es relacionarlo con nuestra salvación. Decir que Dios se revela (en Jesús) no es algo meramente intelectual, sino que apunta a cambiar nuestra propia vida. Y una forma de expresar esa relación con nuestra propia vida fueron los títulos cristológicos de los que Sobrino analiza cinco: Sacerdote, Mesías, Señor, Hijo de Dios y Palabra. Cinco o 
treinta, no se puede sistematizar en ellos toda la cristología del Nuevo Testamento. Pero su variedad sí que muestra que "los primeros cristianos fueron relacionando (a Jesús) progresivamente con la totalidad de lo real" (p. 175). La misma multiplicidad de los títulos en el Nuevo Testamento muestra su inacababilidad; por eso es legítimo que épocas sucesivas puedan necesitar y encontrar títulos nuevos (el de Punto Omega de la evolución, en Teilhard; el Hombre para los demás, en Bonhoeffer, y el Liberador, en América Latina).

Establecido esto, hay que constatar también que pronto fueron privilegiados algunos títulos (Señor, Hijo de Dios): "los trascendentes" dirá Sobrino (p. 176), y fueron olvidándose otros como el Siervo, que daban contenido a aquéllos. Esta unilateralidad comporta un peligro, a saber: que esos títulos - perdiendo su relación con todos los demás- sean entendidos desde ellos mismos o desde su significado genérico y no desde Jesús, que es el que verdaderamente les da contenido. Si sólo fuéramos "de los títulos a Jesús", entonces Jesús "no revelaría nada nuevo". Esto lo mostrará Sobrino, comenzando su comentario con el título de Sacerdote.

El Sumo Sacerdote es el título de la humanidad, pero "no una humanidad cualquiera, sino la que se ejercita a manera de fraternidad y solidaridad". El Mesías es título de salvación, pero esa salvación "incluirá esencialmente dar respuesta a las esperanzas populares de los pobres, débiles y víctimas". El señorío de Jesús "será servicio salvífico que, en último término, deposita en nuestras manos su cuerpo histórico. La filiación de Jesús es, en definitiva, la del débil, la del siervo, la que le encarna y hermana con el pueblo crucificado". Y lo que tiene de sacramentalidad el que Jesús sea Palabra "proclama que lo humano puede hacer transparente a Dios y que, en definitiva, no es necesario añadir nada a lo humano para transparentar a Dios, aunque haya que concretarlo" (p. 181). De este modo, los títulos "nos introducen en la realidad de Jesús, pero de manera precisa" (p. 181).

Desde este cambio interpretativo, Sobrino obtiene una perspectiva que será decisiva para abordar la dogmática cristológica. El la formula como la perspectiva del "homo verus" (no simplemente el vere homo), y yo creí encontrarla antaño en la perspectiva de la Humanidad nueva, bastante cercana en formulación como se ve. De ahí se deducirá también que al estudiar la cristología "estamos esbozando importantes dimensiones de antropología cristiana" (p. 182).

En los títulos concretos que estudia el autor, reaparece un nuevo círculo hermenéutico: ayudan a comprender la realidad, pero son iluminados desde las preguntas de la realidad. Pondré sólo un par de ejemplos.

El Sacerdote remite a la obra terrestre de Jesús (igual que el Profeta) y a la posibilidad de salvación (o mediación). La tesis de Sobrino es que, en Jesucristo, lo salvador (o mediador) es lo humano "sin añadidos pero con concreciones" 
(p. 186). No lo cúltico, como era típico en las religiones ambientales y en el Antiguo Testamento.

Pero en Jesucristo no hay sólo un cambio en la idea del mediador. Este se da porque hay también un cambio en la idea de Dios. El ser de Dios no está en su distancia, sino en su acercarse, el cual es bueno, libre, gratuito y parcial hacia los débiles.

Este cambio en la noción de Dios cambia la idea de mediación. Siguiendo los estudios ya clásicos de $\mathrm{A}$. Vanhoye sobre la carta a los Hebreos, muestra que Cristo está más cerca de Dios (que por ejemplo los ángeles), precisamente, porque está más cerca de lo humano. El sacerdote antiguo debía ser alejado, riguroso y era frágil. Jesús aparece en la carta como "semejante a sus hermanos", misericordioso y santo. No es mediador por algo sobrehumano o por alguna realidad añadida a lo humano, sino por su modo concreto de ser humano: en la misericordia, en la fidelidad y en la entrega de su vida. Es decir, no sólo por ser humano, sino por ser hermano: la misma carta que comienza llamando a Jesús "Hijo", sigue diciendo que él llama a los hombres "hermanos". Y esta dualidad se corresponde con la de los sinópticos "Abbá y reino".

Dejamos los títulos de Mesías y Señor - menos novedosos en esta obrapara pasar al de Logos o Palabra. "Con él se continúa la línea de pensamiento de que en Jesús ha aparecido Dios" (p. 277). Siguiendo a los exegetas clásicos, el autor va recorriendo primero el significado veterotestamentario de "la Palabra" (donde subraya sobre todo su carácter interpelador —en oposición a lo que "se ve", y se impone por eso mismo- y, por tanto, la posibilidad de rechazar esa interpelación, dejando así de relacionarse con Dios). Y luego su significado en el prólogo del cuarto evangelio que, arrancando desde la preexistencia y la creación, traza "una historia" de la Palabra que marca "el devenir de Dios": su hacerse debilidad ("carne") en la historia y la reacción de los seres humanos a ese acercamiento definitivo.

Pero lo que interesa más a Sobrino tras la exposición bíblica es señalar que, en el título de Palabra, predomina el aspecto de "buena noticia" (vida) sobre el de revelación (verdad). Jesús como Logos no es sólo información, sino autodonación de Dios. El interés del Nuevo Testamento no es especulativo, sino salvífico, y "de ahí que se analice su relación con Dios, fuente última de salvación" (p. 287). Lo que afirma el prólogo de Juan es que

sobre esta tierra de tinieblas ha aparecido luz, que sobre este mundo de muerte ha aparecido vida y que en este mundo de provisionalidades... ha aparecido lo definitivo. Visto desde nosotros, dice que en este mundo se puede ser hijos e hijas de Dios, todo ello como don y gracia. Se puede ser "humano" (p. 293). 
La afirmación fundamental del prólogo joánico es, evidentemente, que "podemos conocer a Dios", pero también que el camino para eso es la vuelta a "la carne" de nuestra historia, ("para captar el Prólogo como buena noticia hay que captar lo humano no meramente en su sentido factual, sino específicamente como 'sarx', lo débil, lo que necesita de la misericordia fiel", p. 294), y que lo que encontraremos en esa vuelta a la historia es "que Dios nos ama tal cual somos, humanos, débiles, también pequeños" (p. 294). Si esto puede ser buena noticia para todos los hombres, lo es aún más para los pobres.

Precisamente por eso, Dios, al revelarse, no enseña meramente "a saber", sino que enseña "a aprender". "La Palabra no es letra sino Espíritu" (p. 290) y, precisamente por eso, "tiene que ser completada" en una dialéctica perenne entre pasado y presente. Un Dios y un Cristo que sólo tuvieran un ayer, "que no tengan un 'hoy', que no hablen, serían un triste Dios y un triste Cristo" (p. 291).

La Palabra se encuentra, por tanto, en esa dialéctica entre pasado y presente, y entre buena noticia y verdad. Establecida la primacía del primer miembro, Sobrino expone también que el principal contenido de la Palabra como "verdad", más que algo fundamentalmente noético (que podría convertirla en "buena noticia" sólo para intelectuales) es algo radicalmente profético: su enseñanza no lleva a pasar meramente de la ignorancia al conocimiento sino, más fundamentalmente, de la mentira a la verdad (p. 297). El enemigo de la verdad en el cuarto evangelio es aquel que es "homicida y embustero" (y Sobrino precisa el orden: primero se aniquila al otro y después se miente sobre ello). "La denuncia dramática que recorre el evangelio (de Juan) es que se puede pervertir el concepto de Dios hasta el punto de intercambiarlo por un principio de muerte y mentira" (cita de J. Barreto, en p. 298).

Sobrino concluye subrayando que esa revelación sigue plenamente vigente en el mundo actual, donde uno tiene de nuevo "la sensación de estar ante el pecado contra el Espíritu Santo" (p. 299). La oposición activa a la revelación de Dios, la mentira del mundo, es tan grande y tan poderosa que sólo un acontecimiento muy especial puede revertir la dinámica de esa mentira y abrir a la honradez con lo real. En el Nuevo Testamento, esa fuerza es la cruz de Cristo. En nuestros días, "el mundo de los pobres y de las víctimas es el que abre los ojos a la verdadera realidad, el que vence sobre la mentira y no sólo supera la ignorancia. Y entonces se puede captar mejor la revelación de Diọ" (p. 300).

Jesús como "Buena Noticia". Concluidos los títulos bíblicos, acuña el autor uno propio: el de Jesús como "evangelio" que, hasta cierto punto, puede ser una variante del de "Salvador", pero con unos matices enriquecedores referidos no sólo al hecho de salvar, sino al modo de hacerlo. Para describir ese modo, Sobrino echa mano de la expresión más originaria: "evangelio: buena noticia". Y aclara que buena noticia es el anuncio de Jesús (el reinado de Dios y su paternidad), buena noticia es también su resurrección, pero, además de eso, es 
buena noticia el modo de ser de Jesús. Insinúa también que ese "modo de ser" parece sugerirlo el Nuevo Testamento con el título de "Nuevo Adán" (a lo que este recensionador podría añadir que Sobrino viene a terminar su cristología bíblica, precisamente allí donde yo comencé la mía: con "la realidad del hombre nuevo"). Y todo esto lo lleva a establecer una dimensión creyente muy decisiva, pero olvidada por la teología: junto a la ortodoxia y la ortopraxis es importante lo que Sobrino llama "ortopatía" (y yo mismo califiqué ya hace años como "ortoestética'): el hecho de que la misma realidad de Jesús, además de enseñar y llamar, "causa gozo".

No hay que temer aquí ninguna reducción horizontalista de la fe. En fin de cuentas, como aclara el autor, la fe no es sin más la aceptación de una interpretación o de un testimonio, sino que "es en definitiva la confrontación y la aceptación, en confianza y disponibilidad, de una realidad histórica que lleva más allá de sí misma y que entonces sí que puede ser interpretada trascendentemente y ser objeto de fe" (p. 305). Las cristologías actuales no acaban de marcar esa diferencia entre que Jesús sea salvación por lo que es, pero también "por el modo como lo es". Esto resta relevancia al mensaje cristiano. Y sin embargo, el Nuevo Testamento no se cansa de repetir que "pasó haciendo el bien y consolando a los afligidos", que "no se avergüenza de llamar hermanos a los hombres" o que en él "ha aparecido la humanidad y la benignidad de Dios".

Esto lleva al autor a preguntarse qué es lo que impacta hoy de Jesús, en una hora histórica marcada, a la vez, por la secularización y por el desencanto. Siento no poder reproducir los dos largos párrafos (pp. 309 y 310) que responden a esa pregunta y de los que sólo podré citar aquí el comienzo y el fin.

De Jesús impacta la misericordia, y la primariedad que le otorga: nada hay más acá ni más allá de ella, y desde ella define la verdad de Dios y del ser humano... Jesús es a la vez hombre de misericordia (misereor super turbas) y de denuncia profética ("ay de vosotros los ricos"), hombre de reciedumbre ("quien quiera venir en pos de mí tome su cruz y sígame") y de delicadeza ("tu fe te ha salvado"), hombre de confianza en Dios ("Abbá, Padre") y de soledad ante Dios ("Dios mío ¿por qué me has abandonado?").

De este modo, Jesús hace central "lo obvio" (p. 312), con una expresión que es también central en el pensamiento de Jon Sobrino. Y esa buena noticia del "modo de hacer" de su persona, se traduce socialmente en la buena noticia del modo de hacer del cristianismo primitivo, que se refleja en "el poder sentarse a una única mesa los que durante siglos habían estado separados: pobres, paganos, esclavos, mujeres, los despreciados de Israel y los marginados del imperio" ( $p$. 312).

Nada más, pero también nada menos que eso. 


\section{La dogmática conciliar}

Establece Sobrino que los textos de los concilios son "útiles, normativos, limitados y peligrosos". Esto último debido a que emprenden "un camino novedoso" (p. 317). Su mayor valor radica en el empeño por juntar "trascendencia e historia"; lo impensado de Dios y la realidad como mediadora de salvación. Esta atención "a la realidad" le permite establecer que nuestro mundo es "masivamente una realidad de víctimas" y de algunos millones de hombres conscientes de ello. De eso no puede prescindir ningún pensar honesto, pero menos un pensar cristiano. Si Jesucristo es Salvador y Mesías, cualquier afirmación sobre él tendrá algo que decir sobre su pueblo crucificado y éste sobre aquélla. Esto ayudará a comprender la radicalidad de algunos contenidos del dogma, a la vez que pone de relieve algunas lagunas (las principales son: la ausencia del reino, de la vinculación de Jesús con él y de los pobres como sus destinatarios). Cree además Sobrino que la óptica de las víctimas "ayuda a replantear mejor el tema del universalismo cristiano, que quizá no es un tema 'de conceptos' sino de vinculación a la realidad" (pp. 319-320).

Dentro de este marco se dan tres pasos: (a) una comparación con el Nuevo Testamento, que detecta una concentración en la constitución ontológica de Jesús, con menoscabo de su historia y de su resurrección como acontecimiento escatológico. La cristología quedará entonces reducida a la noción de encarnación y el Nuevo Testamento será utilizado más como suministrador de pruebas que "como narrador de la historia de Dios con los hombres, en Cristo" (p. 325). (b) Se constata un divorcio entre la praxis y la cristología teórica: Jesús sólo es presentado como objeto de fe, y no (de acuerdo con el Nuevo Testamento) "como persona cuya realidad debe ser reproducida en la propia vida" (cfr. p. 328 , donde comenta que el que todos los apóstoles murieran mártires es ahora sólo un dato de información histórica, carente de significatividad teológica). Y (c) también se percibe un distanciamiento entre la cristología y la realidad de las comunidades, que tampoco se daba en el Nuevo Testamento. Es innegable que la cristología patrística fue "popular", en el sentido de que "estuvo en el ambiente", pero no en el sentido de que expresase la realidad de las comunidades, las cuales sólo son "mero destinatario" de la reflexión de unos pensadores, más semejantes "a los pensadores del mundo helénico que a los autores de los sinópticos" (p. 331). En comparación con esto, el Nuevo Testamento no sólo "transmite doctrina" (respondiendo a la pregunta de qué puedo saber), sino también esperanza, exigencia de compromiso y celebración. Mientras que ahora, al no ser la realidad de las comunidades principio hermenéutico de la cristología, "lo histórico-concreto de Jesús se hará cada vez más irrelevante para ésta" (p. 332).

Pero, pese a estas diferencias, la dogmática conciliar mantiene un punto de contacto con el Nuevo Testamento, que es el interés salvífico. Ello debe ser subrayado, aunque su noción de salvación sea demasiado "última": "no está en 
la línea recuperada en la Gaudium et spes o en Medellín", lo cual la hará verse ligada cada vez más sólo "al derramamiento de la sangre de Cristo en la pasión" y "reforzará la tendencia de la teología de la encarnación a desprenderse de la historia y a recogerse en el instante intemporal de la unión del Verbo con la humanidad" (cita de J. Moingt, a quien el autor sigue de cerca en estas páginas).

Para corregir esas unilateralidades, habría que mostrar mejor la convergencia entre divinización y humanización, introducir (junto al concepto de salvación en singular) "el concepto jesuánico de salvación en plural", "plantear de forma distinta a la de la patrística la apropiación personal de la salvación" (p. 337), y hacer que el reino de Dios reaparezca en las fórmulas cristológicas, junto con la relación trascendental entre Dios y el reino, que es lo que permitiría comprender la salvación también "como salvación de la historia por parte de Dios" (p. 339), y no sólo como superación de la incertidumbre, de la mortalidad y de la materia (que es lo que el mundo helénico buscaba).

Este marco previo me parece más importante que el estudio de las distintas fórmulas dogmáticas, de las que añadiremos una palabra para concluir esta presentación.

Sobre la fórmula de Nicea. Tras un buen análisis del origen y significado de la fórmula Sobrino señala que Nicea no dice sólo algo sobre la divinidad de Jesucristo, sino (más importante aún) sobre la divinidad de Dios. Por ejemplo, "el rechazo de un Dios que sea ajeno a la historia y él mismo sin historia" (p. 371). Pero este rechazo se realizará sólo a medias, puesto que el Hijo será declarado "consustancial" por lo que Jesús es y no por lo que Jesús hace, con lo cual la helenización del cristianismo se supera en parte, pero se realiza en otra parte: la comprensión de Dios no conserva eficientemente la "parcialidad" del Dios de Jesús y sigue guiada "por universales más que por concretos" (los de Jesús) (p. 374).

Pero a pesar de eso, se da ya entrada en la noción de Dios al sufrimiento lo cual, evidentemente, no carece de importancia para las víctimas. Ello permite destacar el valor religioso de la fórmula nicena: "en la realidad de Dios hay algo esencial de misterio, no controlable por tanto por la razón. Y en cuanto. se le deja ser no controlable, sino más bien controlador de la razón, Dios se muestra como Dios" (p. 378). A pesar de todo, ello no impide que ese Dios de Nicea (con otra feliz formulación del autor), aunque ya no sea confirmación de nuestra idea de Dios, sí que es todavía modificación controlable de ella. No llega a ser estricta revelación. Con otra formulación ya conocida y muchas veces utilizada por Sobrino, el "Deus semper maior" tendría que ser además el "Deus semper minor".

Aun con esta limitación, Sobrino puede preguntarse si las víctimas creen en el Dios de Arrio o en el de Nicea. Y, mediante una comparación de textos, tanto 
de la actual (y erudita) disputa en torno a la teodicea, como de comunidades populares y maltratados salvadoreños, se llega al establecimiento de dos términos muy importantes para la soteriología: alteridad y afinidad. La verdadera salvación parece incluir los dos y eso se expresa sólo en la fórmula de Nicea. Ahí estaría su perenne valor, a pesar de los límites expuestos.

Sobre la humanidad de Jesús. Si Nicea presupone, por tanto, un "pathos de radicalidad", los concilios posteriores revelan un "Pathos de realidad y de totalidad". Este es el valor de las luchas por salvar la plena humanidad de Jesús, tras el primer concilio, aunque el autor no deja de señalar lo raro que resulta que haya que luchar tanto por salvarla: ¡eso habría sido algo impensable en la época del Nuevo Testamento!

El afán de realidad se expresa en todas las luchas en torno a la verdadera corporalidad. Verdadera alma, verdadera naturaleza y verdadera voluntad humanas de Jesús. En contraste con aquellas luchas históricas, Sobrino cree que la Iglesia está hoy más atenta al peligro de "reducir" la divinidad de Jesús que al de "desvirtuar su humanidad" (p. 389); esto puede deberse a una "falta de concreción de lo humano" (p. 405) en las fórmulas dogmáticas, pero es algo que hoy puede repercutir negativamente en "la irrealidad del ser y de la misión de la Iglesia” (p. 390, cursivas en el original). La plena humanidad de Jesús implica no sólo que "Dios deja a lo humano ser humano", sino también que "lo humano verdadero es ya en sí mismo salvación” (es decir, que Cristo es no sólo "vere homo", sino además "homo verus", p. 391). Esa verdad última de lo que es ser hombre la conocemos porque ha aparecido en Jesús, en su relación constitutiva con Dios, en su misión, su talante y su destino.

El afán de totalidad se expresa en las luchas por el modo de unión de lo divino y lo humano en Jesús. Con sólo decir que Jesús es "Dios y hombre" no se ha dicho todavía quién es él, si no se aclara el modo como lo es. Esto es lo que hizo que, tras los dos primeros concilios, no se cerraran todavía las discusiones cristológicas, que acabaron llevando hasta Efeso y Calcedonia. Su enseñanza implica no sólo un "pathos" de totalidad (Jesús lo es todo: uno y dos), sino un respeto con lo real al no pretender volver comprensible esa relación (es el sentido de los cuatro adverbios negativos: inconfuse, indivise, etc., que acompañan a la fórmula calcedonense). Todo eso debe ser reconocido, más allá de las dificultades de comprensión que acompañan hoy a la fórmula, y que exigen una reflexión suplementaria.

Sobre Calcedonia y sus dificultades. Para superar esas dificultades, Sobrino propone dos cosas: (a) que, desde el punto de vista epistemológico, se mire la fórmula calcedonense como una "doxología", es decir, como un punto de llegada, en el que acaba expresándose una experiencia de fe (por ejemplo, la coexistencia de trascendencia e historia). Esto es lo que hicieron las fórmulas neotestamentarias. Y (b) desde el punto de vista "metafísico", que se atienda 
más a su estructura formal que a sus contenidos concretos (cfr. p. 413). Esto quiere decir que, en los varios elementos que constituyen la realidad y que parecen difícilmente unificables, la "realidad última se constituye y se unfica como tal, manteniendo y respetando sus elementos por 'inunificables' que parezcan" (p. 414). De esto hay atisbos parciales en nuestras experiencias de lo real ("reverberos de Calcedonia" los llama el autor). Y esos atisbos se dan tanto a nivel personal (la intuición de la "no dualidad sin identidad") como a nivel social, en un párrafo que vale la pena reproducir.

[En la praxis de liberación] se dan dos elementos diferentes, que podemos formular como fe religiosa (elemento transcendente) y lucha por la justicia (elemento histórico). Pues bien, pronto apareció la tentación de que una.dimensión se mezclase con la otra hasta absorberla y desvirtuarla, o que cada una de ellas siguiese su camino sin potenciarse. La lección es que tanto una cosa (la mezcla o el recorte que hace desaparecer la identidad propia de cada dimensión), como la otra (la división o separación que no pone en relación una dimensión con la otra) eran nocivas para la liberación. Dicho en lenguaje sencillo: es bueno para la liberación (la realidad una) que existan las dos dimensiones (fe y justicia). Es bueno que cada una respete la identidad de la otra sin absorberla... sin forzar una dimensión a favor de otra y sin que se separen (pp. 414-415).

La superación de estas dificultades de intelección ayuda a actualizar los valores de la fórmula calcedonense, pero pone más de relieve sus límites: falta de concreción (se habla en abstracto de divinidad y humanidad, como si fuesen términos ya conocidos), ausencia de la historia, y falta de relacionalidad, tanto de la relación de Jesús al Padre, constituida por la entrega, como de su relación al reino, constituida por la praxis.

No hay particular novedad en los datos históricos que acompañan esta exposición de los concilios. Pero si vuelve a haberla en lo que constituye para el autor la clave que unifica esa doble lectura que hemos llamado "formal y doxológica" de la fórmula calcedonense, y que para Sobrino está en el seguimiento de Jesús. Tanto que a esa clave dedica un nuevo capítulo (el 19), empalmando así con el primer volumen de esta obra: el seguimiento de Jesús no es sólo factor epistemológico imprescindible para conocer al Jesús "histórico", sino también para comprender la dogmática.

Veamos esto para concluir nuestra exposición.

Como fórmula "de totalidad", la enseñanza del calcedonense ayuda "a comprender la unidad radical de la realidad, de lo humano y la divino" (p. 441). La adopción de esa actitud formal, beneficiaría tanto a la mística (unificación sin desaparición) como a la antropología (armonía de las mil diversidades de lo humano), como a la sociología (lo que, en el caso de la Iglesia, sería la evitación 
del "docetismo eclesial"). Hay que prescindir aquí de los datos bíblicos e históricos que acompañan la exposición de Sobrino, puesto que son más conocidos. Baste con señalar que el mismo afán de totalidad se revela en fórmulas como la del "Logos-sarx" o la de la "recapitulación universal" (el autor prefiere hablar de "vicariedad", que a mí me gusta menos) de todo en Cristo.

Como fórmula "doxológica", la enseñanza del calcedonense repite un proceso parecido al de las afirmaciones bíblicas sobre Dios: constatación de acciones históricas, que son remitidas a Dios y permiten decir algo sobre Dios. "El proceso comienza con la realidad humana de Jesús, en principio históricamente constatable". Esa realidad humana es puesta en relación con Dios. Y el proceso termina con la confesión de la divinidad de Jesús (pp. 452-453).

Pues bien, en este camino hay dos elementos esenciales: el camino del conocimiento (que comienza con una realidad de tipo histórico) y la entrega de la razón al final del proceso. En el análisis de estos dos elementos se contienen páginas de las más valiosas del libro (pp. 454-464), que da cierto temor resumir.

El camino de conocimiento no es sólo teórico, sino "histórico". Aquí entra en juego el seguimiento que permite captar, a la vez, una afinidad y una alteridad: "el ser-así de Jesús se conoce en profundidad desde el ser-así nosotros" y ese "ser-asî", se muestra abierto a la trascendencia histórica. Abierto quiere decir que ese camino parece ofrecer "ultimidad" (aunque a su vez pueda ser visto también como ilusorio), parece abrirse a "más vida", permite experimentar que "la realidad da más de sí".

El decantarse por la primera opción (camino abierto a la trascendencia) y no por la segunda (camino ilusorio) es lo que la teología tradicional calificaba - hablando de la fe-como "obsequium rationabile" y Sobrino parafrasea como "castidad de la inteligencia". Pero quiere decir también (y esto es muy importante) que "el criterio de razonabilidad de la fe está relacionado con el Jesús al que se sigue... y no sólo ni en directo con el Cristo (inverificable) al que se confiesa en la fe" (p. 456, subrayado mío). Si no se ponen límites al seguimiento se está recorriendo un camino que puede llevar a la confesión de la divinidad de Jesús. Pero eso es porque ya el conocimiento de Jesucristo que se da en el seguimiento necesita de entrega. $Y$ cuando esa entrega se da, hay siempre una proclamación de Jesús como realidad última divina.

Camino y entrega constituyen así lo que Sobrino llama "la experiencia cristológica", que luego habrá que formular con dificultad y con diversidades. Pero esa entrega, por su mismo carácter de "obsequio" o de "castidad de la inteligencia", requiere la ayuda del Espíritu. Con otra fórmula feliz, Sobrino escribe que "el seguimiento es el cauce que hay que recorrer y el Espíritu es la fuerza para recorrerlo actualizadamente" (p. 459). Y aprovecha para advertir que el camino hacia Jesucristo no es una acción del Espíritu sin seguimiento, sino 
"un seguimiento con espíritu": ser espiritual, por tanto, no consiste en algo que se decida en el hablar acerca del Espíritu, sino en ser y hablar en el Espíritu y con el Espíritu.

Esta última constatación sirve para que Sobrino retome una expresión que le gusta añadir a la célebre triada de Zubiri y Ellacuría: no sólo hay que "hacerse cargo" de la realidad, "encargarse" de la realidad y "cargar" con ella, sino que también es preciso "dejarse cargar” por la realidad. Cristología y pneumatología, o cristología y gracia quedan así indisolublemente unidas.

\section{La identidad cristiana}

Se puede comprender entonces que Sobrino añada un epílogo cuyo título viene a resumir no ya lo que ha querido ser este libro y lo que para él define, si no toda la identidad cristiana, al menos la identidad "cristológica", sobre todo lo que es él mismo y lo que propone al lector: "recordar y caminar".

Recordar la originalidad indeducible de Dios tal como lo revela Jesús, la centralidad del reino de Dios, que deriva de lo anterior y, sin embargo, ha sido demasiado olvidada o malentendida por el pensar cristológico, y recordar también el estatuto teologal de los pobres, que brota a su vez de la centralidad del reino.

Y caminar en la historia, hacia el futuro de Dios, y abriendo quizá caminos que otros podrán recorrer. Caminar "sin poder hacer otra cosa", contra los que pretenden haber llegado ya desde la gratitud porque creen haber encontrado a Dios, y contra los que pretenden que no queda más camino que la protesta o la blasfemia. Si se quiere hablar del cristianismo como religión, habrá que decir que es una religión “del caminar en la historia" (p. 476).

Sencillo y espléndido programa que ya no hay lugar para desarrollar, pero que parece recoger aquellas palabras del profeta Miqueas que el autor ha citado tantas veces: "el Señor reclama de ti, tan sólo que practiques la justicia, que ames de verdad y con ternura, y camines humilde con tu Dios".

Sólo queda hacer un balance sencillo para concluir esta presentación.

\section{Balance}

Lo primero que habría que decir de este libro está ya contenido en su título y en su subtítulo. Es un libro profundamente creyente. Precisamente por eso, realiza en mi opinión perfectamente el conocido círculo: crede ut intelligas, intellige ut credas. La fe abre perspectivas de intelección que devuelven valor a muchas fórmulas. Y la misma seguridad de la fe abre perspectivas de interrogación y de crítica, sin temor a reconocer los límites de fórmulas que, por otro lado, son aceptadas y valoradas. Es, en este sentido, un modelo "formal" de buen hacer teológico. 
Pero, a pesar de eso, se trata, en segundo lugar, de una fe que no tiene como horizonte primero la comprensión, sino su carácter de buena noticia: "a lo largo de los dos libros - escribe Sobrino en la conclusión- hemos tratado de mostrar que, desde Jesucristo, la fe cristiana tiene como contenido central una buena noticia" (p. 465). Una buena noticia que no es "a gusto del consumidor", sino que está emparentada con el seguimiento. Lo que hace que la teología no sea una ciencia "para intelectuales", sino primariamente, una ciencia "para las víctimas".

Se trata por eso de una fe de la cual se da razón "desde las víctimas". La misma seguridad creyente de su autor, unida a esa "honradez con lo real", que se ha convertido en un "primer principio" de su teología, enmarcan el libro en la profunda convicción de que si Jesús es efectivamnte "el Mesías", todo lo que de El se diga ha de tener un signficado (antes que para ningún otro), para aquellos más necesitados de mesianidad, en esta realidad nuestra. Sin que esto signifique una reducción del mesianismo, pero sin que tampoco signifique su evaporación hacia espiritualismos que no pueden liberar y que sólo pueden ser esgrimidos por aquellos que desconocen lo que es ser víctima de esta historia. Todo ello hace que el libro recupere con facilidad infinidad de elementos perdidos por lo que cabría llamar "el reduccionismo burgués" de la fe cristiana, en los últimos siglos.

Que el libro está escrito desde lo que nosotros llamamos "tercer mundo" se refleja en la sencillez con la que el autor trabaja con "materias primas" importadas del primer mundo. Pero lo llamativo es que con esos materiales "importados" nos devuelve una manufactura teológica de profunda originalidad y de más calidad que casi todos nuestros productos teológicos. Los destinos se invierten y resulta así que el tercer mundo económico se convierte en "primer mundo teológico", para advertencia nuestra.

Quiero decir con esto que, al estar escrito desde las víctimas, el libro se convierte en una propuesta de validez universal, a la que no cabe desautorizar diciendo que es buena "para ellos". Más aún, esa propuesta nos devuelve algo que había sido muy nuestro, y a lo que nosotros hemos sido infieles. Hace escasamente una generación que T. Adorno - reflexionando sobre Auschwitzescribía que, en lo sucesivo, todo pensamiento y toda cultura ( $¡$ no simplemente teología!) que no tenga en cuenta esa óptica, "se convierte por anticipado en algo de la misma calaña que la de la música de acompañamiento con que las SS gustaban de cubrir los gritos de sus víctimas" (Dialéctica negativa, p. 365). Sobrino, por su modestia, no se atreve a decírnoslo así. Pero nosotros no podemos eludir esa interpelación, dirigida a toda nuestra "cultura" occidental de la hora presente.

¿Alguna crítica? Mientras redactaba esta recensión tuve ocasión de releer (por otros motivos) el esbozo de una dogmática de K. Barth. Y se me ocurrió 
pensar que quizás el suizo habría exclamado ante la obra de Sobrino: "jaquí falta el pro nobis;": ese "por nosotros" que Barth esgrime allí decisivamente como el pro me luterano. Me imaginé entonces al autor respondiéndole a Barth: donde faltan las víctimas, tampoco hay un auténtico pro nobis, sino sólo un cómodo pro nostris. Esto es fundamental para plantear el problema de la salvación: una renuncia a la pregunta por la propia salvación, para comenzar preguntando por la de los más necesitados. Hay en esto algo profundamente crítico, pero de una cristología puesta en práctica, ejercitada (recordemos que así es como aparece la fe en la resurrección, tal como expusimos). Pero ello no impide que, para un segundo momento, siga pendiente la cuestión: el día en que las víctimas puedan ser sencillamente seres humanos como nosotros, reaparece la pregunta por la salvación. Esto está ya suficientemente insinuado en el libro (es el tema de la universalidad desde la parcialidad), pero no obsta para que podamos terminar señalando y deseando que todavía el autor la emprenda con una soteriología explícita. Así sea. 